\title{
O trabalho do/a assistente social no atendimento à população transgênero e travesti
}

\author{
The social worker's job with \\ transgender and transvestite people
}

\author{
Bárbara Cristina Silva Pereira ${ }^{a}$ \\ (D https://orcid.org/0000-0002-2681-9730 \\ Silse Teixeira de Freitas Lemos ${ }^{b}$ \\ (D) https://orcid.org/0000-0003-3437-0141
}

Resumo: Este artigo tem como objetivo analisar os desafios e as possibilidades de trabalho do/a assistente social junto à população transgênero e travesti. Trata-se de uma revisão integrativa de literatura, a qual utilizou as bases de dados SciELO, Redib e Portal de Periódicos Capes. Observou-se que a discussão se apresenta alinhada ao projeto ético-político, considerando-o basilar para a compreensão dos desafios na realidade concreta e também na busca por enfrentá-los.

Palavras-chave: Trabalho. Assistente Social. Transgênero. Travesti.
Abstract: This article aims to analyze the challenges and possibilities of social worker's job with the transgender and transvestite people. It is an integrative literature review, which used the databases of SciELO, Redib and "Portal de Periódicos Capes". It was observed that the discussion is aligned with the ethical-political project, considering it to be essential for understanding the challenges in the concrete reality and also in the search for facing them.

Keywords: Work. Social Worker. Transgender. Transvestite. 


\section{Introdução}

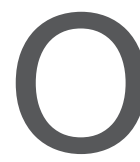

presente artigo tem como objeto de estudo a análise dos desa-

fios e das possibilidades de trabalho do/a assistente social no atendimento à população transgênero e travesti. Parte-se de inquietações advindas do treinamento em serviço, possibilitado através da Residência Multiprofissional em Saúde, no que tange à atuação desses profissionais junto à referida população, compreendendo que o processo de trabalho deve ser analisado em sua totalidade dinâmica. Trata-se, também, de um tema atual e recente, o qual tem sido pouco explorado pela categoria profissional.

A transgeneridade caracteriza-se quando a pessoa não se identifica com o sexo biológico designado ao nascer, ou seja, quando este não corresponde à identidade de gênero daquela pessoa (Bento, 2008). A identidade de gênero representa como alguém se sente e se apresenta no mundo, sem que isso implique uma relação direta e inevitável com o sexo biológico. Para além desses conceitos, uma pessoa também pode se identificar com aspectos sociais de mais de um gênero, flutuando entre ambos, ou com nenhum gênero normativo binário (Silva; Lehfeld, 2019).

A travestilidade é interpretada por Marinho (2017) como uma identidade variante do feminino, considerando que as travestis vivem e se apresentam socialmente como pertencentes ao gênero feminino. Mais do que um conceito normativo, é preciso compreender o contexto histórico e político que o termo travesti tem carregado na sociedade brasileira. A identidade travesti, sob um olhar político, coloca em xeque a lógica binária de gênero, além de ser uma construção latino-americana.

Berenice Bento (2006) afirma que o sistema binário de gênero produz e reproduz a ideia de que o gênero, determinado quando uma criança nasce, é refletido a partir do sexo biológico. Os preconceitos, as discriminações e as violências que as pessoas trans e travestis sofrem e de que são vítimas, traduzidos por meio do fênomeno da trans/ 
travestifobia, sustentam-se em uma lógica normativa de controle dos corpos, que traz, igualmente, benefícios ao modo de produzir e viver em uma sociedade capitalista.

O binarismo de gênero pressupõe uma ideologia que afirma que homens e mulheres são radicalmente diferentes e que essa diferença está assentada no sexo biológico, portanto, imutável e inquestionável. A população trans e travesti faz parte da parcela da população usuária do Serviço Social e é fortemente afetada pelo binarismo de gênero e pelo conservadorismo das relações sociais (CFESS, 2016). Aqueles que se reconhecem dentro da transgeneridade, da travestilidade e do não binarismo de gênero sofrem com as consequências de uma sociedade cisgênera, heterossexista e patriarcal.

O profissional de Serviço Social deve estar capacitado para lidar com essas demandas, a fim de qualificar o atendimento a essa população, fortalecer seus direitos e as suas diversidades de existência. A Resolução n. 845, de 26 de fevereiro de 2018, do Conselho Federal de Serviço Social (CFESS), aponta que o trabalho do/a assistente social deve se pautar pela integralidade da atenção à saúde, levando em consideração as diversas necessidades dos sujeitos, indo além de um modelo baseado no atendimento focalizado em procedimentos hormonais ou cirúrgicos.

Além disso, também refere que esses profissionais deverão contribuir para "[...] a promoção de uma cultura de respeito à diversidade de expressão e identidade de gênero, a partir de reflexões críticas acerca dos padrões de gênero estabelecidos socialmente" (CFESS, 2018, p. 2). Tendo isso em mente, considera-se fundamental discutir os desafios que permeiam o trabalho do/a assistente social no atendimento a esse público específico, analisando as possibilidades de intervenção diante da realidade concreta.

Posto isso, este artigo está estruturado da seguinte forma: após a introdução, apresenta-se o percurso metodológico utilizado para concretizar o objetivo deste estudo. Em seguida, apontam-se os resultados alcançados 
e as discussões pertinentes após análise do conteúdo encontrado. Nesse momento, abordam-se algumas reflexões sobre o projeto ético-político do Serviço Social e a "questão de gênero", a trans/travestifobia como expressão da questão social e, por fim, os desafios e as possibilidades de trabalho para o/a assistente social.

\section{Percurso metodológico}

O presente estudo trata-se de uma revisão integrativa de literatura, a qual, por sua vez, proporciona a síntese de conhecimento e possibilita a análise de pesquisas relevantes sobre determinado tema, além de apontar lacunas nas investigações e a necessidade de realização de novos estudos (Mendes; Silveira; Galvão, 2008). Nesse sentido, inicia-se com a seguinte questão norteadora: Quais os desafios e as possibilidades de trabalho do/a assistente social no atendimento à população transgênero e travesti?

Foram seguidas as seis etapas do processo de elaboração de uma revisão de literatura integrativa (Ganon, 1987 apud Souza; Silva; Carvalho, 2010): 1) elaboração da pergunta norteadora; 2) busca ou amostragem na literatura; 3) coleta de dados; 4) análise crítica dos estudos incluídos; 5) discussão dos resultados; e 6) apresentação da revisão integrativa.

A busca na literatura e a coleta de dados foram realizadas entre os meses de setembro e novembro de 2020. Os descritores utilizados foram: "Serviço Social", "assistente social", "trans" e "travesti", escolhidos estrategicamente a fim de obter número satisfatório de artigos. Os descritores foram aplicados da seguinte forma nos canais de busca: "Serviço Social" AND "trans", "Serviço Social" AND "travesti", "assistente social" AND "trans" e "assistente social" AND "travesti”. Optou-se pela utilização das bases de dados da SciELO, da Red Iberoamericana de Innovación y Conocimiento Científico (Redib) e do Portal de Períodicos Capes.

Os critérios de inclusão contemplaram artigos científicos completos, em português, que atendessem à questão norteadora desta pesquisa. 
Foram excluídos da pesquisa trabalhos de conclusão de curso, dissertações, teses, resumos, boletins, folhetos, fôlderes, cartilhas, relatórios, livros e publicações duplicadas, bem como aqueles artigos que não tratavam sobre a questão norteadora. Não foi estabelecido critério temporal para publicação dos artigos.

Importante ressaltar que a análise concretizada nesta pesquisa tem abordagem qualitativa e como base o método histórico-dialético, levando em consideração que o objeto de estudo tem relação com os movimentos em sociedade, seus processos de resistência e sua inserção na luta de classes. Utiliza-se a teoria social materialista por compreender que “[...] não são as ideias e as normas que determinam a sociedade, é a realidade, com a concretude histórica das relações sociais e seus antagonismos postos na luta de classes, que determina as normas e ideias" (Santos, 2011, p. 49). Assim, a partir da apresentação do real, realiza-se um esforço para traduzir seus profundos significados no âmbito da consciência.

\section{Resultados e discussão}

Na primeira fase de busca da literatura ou amostragem, foram encontrados 16 artigos na base de dados SciELO, 26 artigos na Redib e 119 artigos no Portal de Periódicos da Capes. Na segunda fase de busca da literatura ou amostragem, realizou-se a leitura de títulos e resumos dos 161 artigos encontrados. Desse modo, conforme os critérios de seleção, foram escolhidos três artigos na base de dados SciELO e 10 artigos na Redib, totalizando 13 artigos, os quais foram lidos na íntegra. Não foram encontrados artigos no Portal de Periódicos da Capes que estivessem de acordo com os critérios de seleção desta pesquisa. Na terceira fase, após leitura e análise do conteúdo dos artigos, a revisão integrativa foi composta por quatro deles, sendo dois artigos da SciELO e dois artigos da Redib. Os materiais duplicados foram descartados (Figura 1). 
Figura 1. Fluxograma de identificação, seleção e inclusão de artigos.

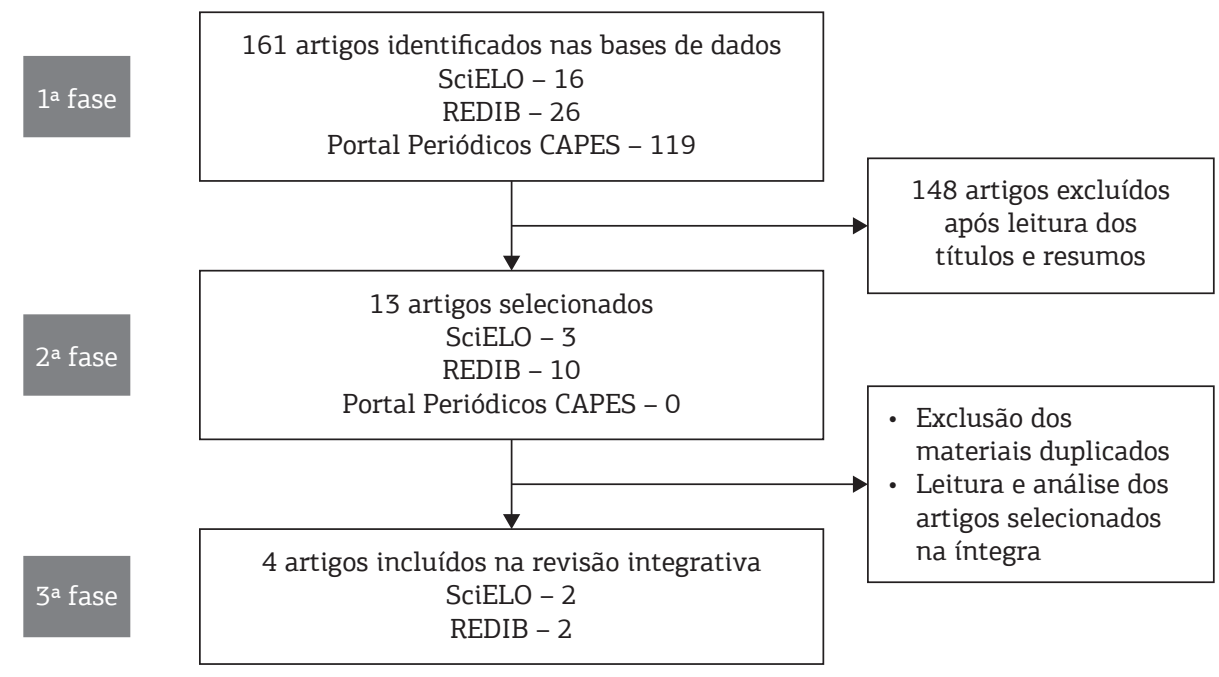

Fonte: elaborado pelas autoras.

Os artigos selecionados foram publicados nos anos de 2017 (25\%), 2018 (25\%) e 2019 (50\%), denotando ser esta uma temática atual, mas também recente e incipiente dentro da categoria profissional. Todos os artigos foram escritos em português e por assistentes sociais. Sobre o grau de formação dos autores, três possuíam pós-doutorado, uma era mestre e três autores eram mestrandos. Todos os artigos utilizaram abordagem qualitativa para análise da temática. Dentre os tipos de estudos, estiveram presentes pesquisas bibliográficas e documentais, assim como revisão de literatura.

Quanto à classificação dos periódicos em que os artigos foram publicados, por eixo temático, todos pertencem à área do Serviço Social (Katálysis, Serviço Social \& Sociedade e Serviço Social em Perspectiva). Nota-se que, no campo de produção, há certa deficiência de materiais publicados em periódicos indexados. Dentre os objetivos dos artigos (Quadro 1), verificou-se centralidade em refletir e discutir o trabalho do/a assistente social com a população trans e travesti, destacando a atuação inserida no Processo Transexualizador no SUS (Artigos 2 e 4). 
$\mathrm{Na}$ análise dos principais resultados, observa-se que os apontamentos direcionam para a compreensão da temática junto ao projeto ético-político da profissão, compreendendo ser este o balizador na busca por reflexões e direcionamentos (Artigos 1, 2, 3 e 4).

Após análise dos artigos e a partir daquilo que mais emergiu durante a leitura, três categorias temáticas foram escolhidas para discussão, quais sejam: 1) Projeto ético-político do Serviço Social e a "questão de gênero"; 2) Trans/travestifobia como expressão da questão social; e 3) Desafios e possibilidades de trabalho para o/a assistente social. A seguir, faremos uma análise sobre cada um dos temas, discutindo os principais achados e contribuições dos artigos que integraram esta revisão.

\subsection{Projeto ético-político do Serviço Social e a "questão de gênero"}

O projeto ético-político do Serviço Social é considerado hegemônico e estabelece as bases para a relação com os usuários dos serviços, com o Estado e com as demais instituições. Seu caráter político está comprometido com a construção de uma nova ordem societária, verdadeiramente democrática, a qual defende a autonomia e a liberdade dos indivíduos e a socialização da riqueza produzida (Netto, 2006).

Dessa forma, o projeto possui relação estreita com os sistemas de transformação e organização social, pois se configura dentro de um projeto maior - um projeto societário - que vai para além do cotidiano e eleva-se a uma ordem de universalidade. Sua perspectiva ultrapassa o caráter de um projeto meramente profissional, voltado apenas "[...] à autodefesa dos interesses específicos e imediatos desse grupo profissional centrado em si mesmo" (Iamamoto, 2009, p. 27).

Nesse sentido, a dimensão ético-política do projeto está voltada para a criação de uma nova forma de vida em sociedade, uma nova ordem social pautada na não dominação ou exploração de classe, raça, etnia e 


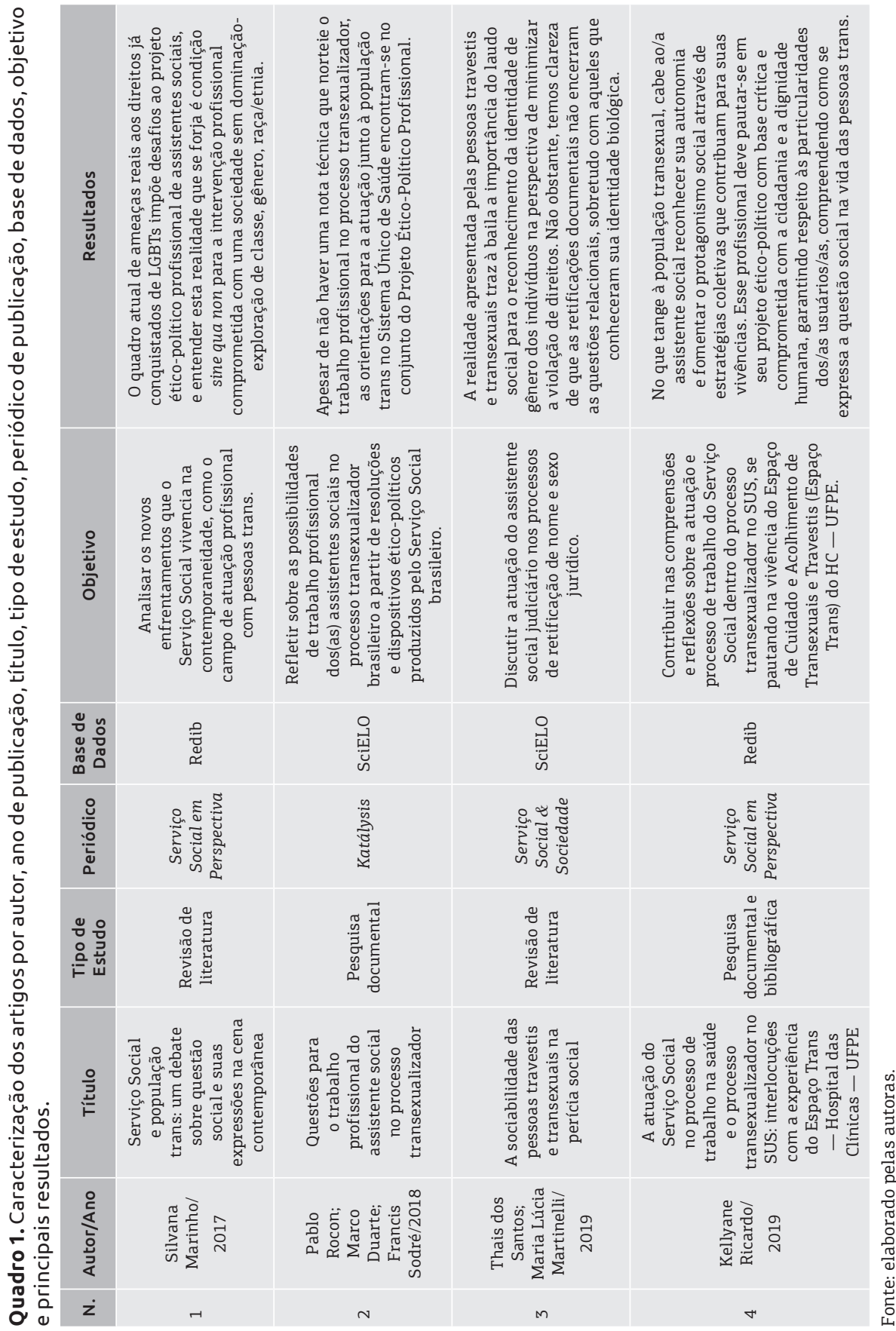


gênero. Posto isso, Iamamoto (2009, p. 29) ressalta que os/as assistentes sociais, como "[...] cidadãos e trabalhadores, tornam-se parte de um 'sujeito coletivo', que partilha concepções e realizam, em comum, atos teleológicos articulados e dirigidos a uma mesma finalidade, como parte da comunidade política".

Assim, é preciso uma articulação entre as dimensões que sustentam o projeto profissional e as mediações do trabalho assalariado, haja vista que os/as assistentes sociais possuem como desafio principal concretizar essas indicações em seu exercício profissional. Como citado anteriormente, esse profissional é dotado de caráter teleológico, numa perspectiva de prévia ideação de suas ações, pensadas criticamente sob a lógica do coletivo e articuladas em seus espaços ocupacionais.

Entre os artigos avaliados nesta revisão integrativa, ao discutir sobre gênero, todos mencionam os direcionamentos ofertados pelo projeto ético-político e os princípios apontados no Código de Ética de 1993.

Os princípios VI e XI do Código de Ética, os quais indicam, respectivamente, o "empenho na eliminação de todas as formas de preconceito, incentivando o respeito à diversidade, à participação de grupos socialmente discriminados e à discussão das diferenças" (Brasil, 2012, p. 23) e o "exercício do Serviço Social sem ser discriminado/a, nem discriminar, por questões de inserção de classe social, gênero, etnia, religião, nacionalidade, orientação sexual, identidade de gênero, idade e condição física" (Brasil, 2012, p. 24), foram lembrados por autores de três artigos incluídos nesta revisão integrativa (Marinho, 2017; Rocon; Sodré; Duarte, 2018; Santos; Martinelli, 2019).

Barroco (2009) afirma que os princípios sozinhos não são capazes de garantir a legitimidade da ética na profissão (considerando que isso seria reduzi-la à concepção legalista e formal, perdendo seu valor real), ou seja, que a sua objetivação é, na realidade, "[...] uma questão de consciência ética e política cuja ampliação requer estratégias da categoria profissional, no sentido de mobilização, de incentivo à participação, à capacitação, de ampliação do debate e de acesso à informação" (Barroco, 2009, p. 14). 
Ao falar sobre gênero, é essencial compreender as desigualdades entre mulheres e homens como históricas, desnaturalizando as relações de poder impostas e construídas socialmente. A partir de uma perspectiva crítica e materialista, as relações sociais de gênero (Cisne; Santos, 2018) não podem ser interpretadas de forma isolada - é preciso conectá-las à estrutura do patriarcado e do racismo, às relações sociais de classe e à divisão sexual do trabalho.

A lógica que estrutura o patriarcado permeia a construção social dos gêneros, delegando modelos do que é ser homem ou mulher na sociedade capitalista (Cisne; Santos, 2018). Quando, por exemplo, a população trans e travesti expressa sua identidade de gênero, contrária ao sexo biológico, foge das normas impostas pelo patriarcado, prejudicando seu sistema. Seus corpos desmentem a suposta naturalidade biológica dos gêneros (Rocon; Sodré; Duarte, 2018), enfraquecendo uma lógica ideológica que oferece subsídios ao capital: o patriarcado.

A força ideológica das relações patriarcais, machistas, heterossexuais e brancas se reproduz constantemente e é apropriada pelas relações sociais capitalistas, “[...] funcionando de modo favorável à exploração da força de trabalho e, quando necessário, à reprodução do conservadorismo" (Cisne; Santos, 2018, p. 44). Assim, é possível compreender que o patriarcado e suas formas de dominação e opressão, ao exercerem controle sobre a subjetividade, o corpo e a sexualidade de mulheres e homens, também atingem a população LGBTQIA+ (lésbicas, gays, bissexuais, transexuais, travestis, transgêneros, queer, intersexuais, assexuais e mais) e, em especial, a população trans e travesti.

O projeto ético-político da profissão está, portanto, diretamente relacionado à luta contra a exploração/dominação de gênero. Ao assumir uma dimensão política se insere nas relações de poder, em um evidente compromisso em favor das classes oprimidas. Reconhecer a trans/ travestifobia como expressão da questão social ultrapassa o âmbito da formalidade, exigindo um esforço para conectá-la à esfera da produção e reprodução material e social. 


\subsection{Trans/travestifobia como expressão da questão social}

O Serviço Social tem na questão social a base de sua fundação ideológica e cultural como especialização do trabalho, sendo seu objeto de estudo e trabalho caracterizado pelas múltiplas expressões da questão social. Para Iamamoto (2000), a questão social é formada pelo conjunto de expressões das desigualdades na sociedade capitalista, as quais emergem em consequência da socialização da produção, enquanto a apropriação dos seus frutos é feita apenas por uma pequena parcela da sociedade.

A questão social tem, portanto, relação direta com a sociabilidade erguida sob o comando do capital, pois incorpora seu modo de produção antagonista e contraditório. À luz da teoria crítica marxista, esse reconhecimento fornece à/ao assistente social os pilares para a compreensão das nuances que surgem com o desenvolvimento dos conflitos entre trabalho e capital - o qual, por sua vez, precisa constantemente buscar novas formas de dominação e exploração para continuar existindo dentro do seu processo de crises cíclicas.

Nas palavras de Netto (2001, p. 45), “[...] diferentes estágios capitalistas produzem diferentes manifestações da 'questão social”. Concordamos com esse autor quando ele sinaliza a inexistência de uma "nova questão social”. Assim, na verdade, o que impera é estabelecer as conexões necessárias para determinar as relações entre as formas emergentes e as modalidades iniciais de exploração.

Trazendo à tona as relações patriarcais de sexo e de gênero na sociedade capitalista, é importante desnaturalizar seus pilares e compreender sua base histórica, social e material. Alguns elementos são fundamentais para a estruturação do patriarcado, dentre eles:

1) as relações sociais de sexo/sexualidade; 2 ) a constituição da família heteropatriarcal-monogâmica associada ao controle sobre a subjetividade e o corpo da mulher e do que é associado ao feminino em toda sua heterogeneidade de expressão; 3) a divisão sexual e racial do trabalho; 4) a violência contra a mulher e a população LGBT (Cisne; Santos, 2018, p. 45). 
Para as autoras, todos esses elementos estão associados e assentados em um sistema regido pelo controle, pelo medo e pela culpa, os quais asseguram a garantia da reprodução da propriedade privada. As condições de exploração, opressão e violências necessitam, por sua vez, de ideologias que sustentem as relações de desigualdade e esmaguem a diversidade humana. A população LGBTQIA+, ao ser associada ao universo feminino ou ao ameaçar a lógica rígida e conservadora das relações públicas e privadas, ameaça também a dinâmica do capital (Cisne; Santos, 2018).

A trans/travestifobia caracteriza-se pelo preconceito e/ou discriminação em função da identidade de gênero de pessoas transgênero ou travestis, configurando-se como uma realidade no Brasil e no mundo. Desse modo, observa-se, a partir do conceito de questão social levantado por Iamamoto (2000) e citado anteriormente, que se trata de um fênomeno expressivo e resultante dos conflitos entre capital e trabalho. No Brasil, o contexto favorável de modernização conservadora corroborou para o aprofundamento das desigualdades de classe, gênero e étnico-raciais.

A manifestação e o aprimoramento da trans/travestifobia configuram-se como expressão da questão social na cena capitalista, à medida que contribuem para o sistema de dominação do capital por meio da exploração do trabalho, da banalização da vida e da permanência dos sujeitos em condições marginalizadas, favorecendo seu extermínio (Rocon; Sodré; Duarte, 2018).

Incluir a temática da diversidade sexual e de gênero no universo do Serviço Social significa reconhecê-la como agenda política — relevante na vida dos sujeitos e com "[...] implicações nas suas condições de vida e de trabalho, bem como nas demandas e respostas profissionais" (Cisne; Santos, 2018, p. 161). É sabido que a trans/travestifobia está presente no ambiente da família, da comunidade, da escola, do trabalho e nas demais instituições, dificultando o acesso e a permanência das pessoas trans e travestis nessas instâncias da vida em sociedade (Marinho, 2017), compreensão que requer sua análise sob a perspectiva de totalidade (Rocon; Sodré; Duarte, 2018). 
O artigo 1 desta revisão integrativa reconhece, a partir do horizonte das determinações históricas, a trans/travestifobia e seus efeitos como expressões da questão social (Marinho, 2017). A autora também demonstra como o Serviço Social, nos últimos anos, tem realizado esforços para inserir a temática da diversidade e identidade de gênero nas suas discussões, considerando sua relevância tanto do ponto de vista intelectual quanto de sua práxis. Contudo, no mesmo artigo, Marinho (2017) chama atenção para o cenário ainda marcado pela pouca produção acadêmica e pela pouca sistematização da prática profissional no que se refere ao assunto.

\subsection{Desafios e possibilidades de trabalho para o/a assistente social}

O ser trans ou travesti envolve um conjunto de fatores que se deslocam do campo biológico e se inserem nas relações sociais, envolvendo a necessidade de imersão e compreensão da família, da comunidade, do mercado de trabalho, da habitação, dos relacionamentos afetivos, da intolerância e do aparato legal que lhes garante direitos. Assim, o trabalho do/a assistente social junto à população trans e travesti configura-se como um rico campo de atuação e intervenções no uso de suas competências profissionais e atribuições privativas (Rocon; Sodré; Duarte, 2018).

O tempo de espera e a dificuldade de acesso às políticas públicas, o predomínio da lógica binário de gênero, o desrespeito ao nome social, os episódios de preconceito, discriminação e violência, a patologização nos atendimentos, o ambiente não acolhedor, profissionais não capacitados, além de outras questões, são desafios que se apresentam no cotidiano da vida concreta de pessoas trans e travestis (Marinho, 2017). Consequentemente, são situações e expressões da questão social que devem ser enfrentadas pelos/as assistentes sociais nos espaços sócio-ocupacionais em que estão inseridos/as. 
Nesse ponto, o conhecimento se apresenta como importante meio de trabalho do/a assistente social. Conforme Iamamoto (2000), as bases teórico-metodológicas funcionam como meio para decifrar a realidade de forma crítica e, assim, direcionar a ação profissional de acordo com a realidade concreta. Esse exercício só é possível através de uma leitura profunda das contradições inerentes ao modo de produzir capitalista, tendo como pilar a reflexão e a suspensão do cotidiano. Para Barroco (2009, p. 172, grifos do original):

O âmbito da vida social mais propenso à internalização dos costumes e valores formadores do ethos dominante é a vida cotidiana: onde os indivíduos se reproduzem enquanto seres singulares, espaço da ultrageneralização, do pragmatismo, do imediatismo, da superficialidade e da heterogeneidade.

Dessa forma, para romper com a barreira do imediato, da aparência e da repetição da vida cotidiana de forma acrítica, é necessário refletir e questionar constantemente a realidade posta, colocando um pôr teleológico nesta tarefa. Quando o profissional de Serviço Social realiza a mediação necessária entre o singular e o universal, ou seja, entre aquilo que se apresenta no cotidiano e o concreto-pensado, aproxima-se do movimento estratégico de intervenção profissional, tendo como base a totalidade dinâmica e complexa das relações sociais (Pontes, 1999).

Essa compreensão é fundamental, pois, diante dos desafios que se apresentam no cotidiano profissional e também dos usuários dos serviços, resgata o sentido da teoria e sua relação com os processos de trabalho do Serviço Social. Nessa direção, é primordial pontuar as implicações da mercantilização da força de trabalho, posto que o/a assistente social é um profissional assalariado (condicionado por elementos externos e internos) e, como tal, também sofre os impactos da alienação do trabalho.

Analisando o artigo 4 desta revisão integrativa, observa-se o cenário de despolitização dos processos de trabalho na área da saúde, marcado pelo contexto neoliberal e conservador, com desafios ao trabalho do/a assistente social. Esse contexto requisita dos profissionais práticas 
fiscalizatórias, patologizantes, moralizantes e imediatas. Prevalece a lógica do individualismo em meio aos ataques às políticas sociais, o que dificulta a consolidação dos princípios ético-políticos do Serviço Social (Ricardo, 2019).

No âmbito da saúde, o artigo 2 destaca os dilemas enfrentados pela população T para acessar o sistema de saúde no Brasil, a exemplo do desrespeito ao nome social, das situações de discriminação, das dificuldades em efetivar o cuidado integral em saúde e da "[...] patologização das identidades de gênero trans como promotores de seletividade nos serviços oferecidos no Processo Transexualizador" (Rocon; Sodré; Duarte, 2018, p. 525).

É preciso resgatar a função social da profissão na divisão social e técnica do trabalho. Entender criticamente este ponto significa não perder de vista os determinantes socioeconômicos e culturais que interferem no processo saúde-doença-cuidado, bem como seguir buscando estratégias político-institucionais que contribuam para o enfrentamento daquilo que se apresenta contrário ao projeto ético-político da profissão e ao projeto de Reforma Sanitária (CFESS, 2010).

Ademais, é preciso expandir o conteúdo de análise da categoria profissional para além do Processo Transexualizador no SUS, compreendendo a participação desses sujeitos nas variadas políticas sociais. Conforme Cisne e Santos (2018), a realidade vivenciada pela população LGBTQIA+, potencializada nas particularidades do capitalismo periférico, traz implicações ao Serviço Social, considerando que, nas diferentes instituições e áreas de atuação, os profissionais se deparam com essa população e com a violação diária dos seus direitos em face da discriminação, do preconceito e da atuação enviesada do Estado.

Iamamoto (2000) lembra que o/a assistente social não se realiza como profissional liberal na sociedade, pois não possui todos os meios financeiros, organizacionais, técnicos e humanos necessários para o trabalho autônomo. Entretanto, através dos elementos constitutivos do processo de trabalho, "[...] interfere na reprodução material da força de 
trabalho e no processo de reprodução sociopolítica ou ideo-política dos indivíduos sociais" (Iamamoto, 2000, p. 69). Tendo isso em mente e diante do cenário de retrocessos de direitos que se apresenta na atualidade, o/a assistente social tem a possibilidade de decifrar estes impasses e exercer sua relativa autonomia na condução dos seus atendimentos e nos espaços que ocupa.

A dimensão pedagógica assumiu diferentes intencionalidades na trajetória do Serviço Social (Abreu, 2002). Alinhada ao projeto ético-político da profissão, tem grandes possibilidades de contribuir para os processos de contra-hegemonia e rompimento com os ideais que fortalecem modos de pensar machistas, heterossexistas e patriarcais. Ao buscar transformar a realidade por meio desta ferramenta, o/a assistente social colabora “[...] para que necessidades e interesses dos sujeitos sociais adquiram visibilidade na cena pública e possam ser reconhecidos, estimulando a organização dos diferentes segmentos dos trabalhadores na defesa e ampliação dos seus direitos" (Iamamoto, 2009, p. 6).

Nesse sentido, outro aspecto a ser destacado é a articulação das demandas da população trans e travesti ao protagonismo dos movimentos sociais. Para isso, é possível acionar competências profissionais vinculadas à mobilização e à participação social. As ações e as atividades voltadas para este propósito têm como finalidade, juntamente às ações educativas, desvendar as situações vivenciadas pelos sujeitos como complexidades de uma totalidade mais ampla - que se reflete como expressão da questão social - e, assim, contribuir para a organização da população, como participantes conscientes e sujeitos políticos (CFESS, 2010).

$\mathrm{O}$ trabalho interprofissional e a articulação entre as redes institucionais também se configuram como elementos fundamentais para a atuação profissional. Conforme Ricardo (2019), as ações intersetoriais e o diálogo com outras instituições são ferramentas importantes para o trabalho do/a assistente social, os quais, acompanhados da promoção da autonomia e do protagonismo dos/as usuários/as, ofereçem resultados positivos. 
Por fim, o compromisso do Serviço Social, em prol dos direitos da população trans e travesti, fica evidenciado nos marcos legais e no arcabouço teórico que direcionam a profissão. Concretizar esses direcionamentos e fortalecer essa luta, no país que mais mata pessoas trans e travestis (Benevides; Nogueira, 2020), são desafios diários, ultrapassando a esfera profissional. Atrelado a isso, o modelo de sociedade neoliberal, que valora a responsabilização do indivíduo sobre si e abomina a diversidade humana, exime o Estado de arcar com os resultados de um modelo de vida e produção que ele sustenta.

As possibilidades de trabalho só poderão ser efetivadas mediante fortalecimento da autonomia do sujeito e de suas potencialidades de vida. Além disso, no leque de disputas de poder e correlação de forças, o distanciamento do conservadorismo é uma tarefa constante, tanto no exercício profissional quanto no processo de formação acadêmica continuada.

\section{Considerações finais}

Diante do exposto, observa-se que o trabalho do/a assistente social junto à população trans e travesti perpassa pela compreensão dos processos de trabalho, inseridos, por sua vez, na dinâmica do modelo de produção capitalista. Qualquer análise descolada da realidade macrossocial ignora os emaranhados contraditórios que sustentam as relações desiguais de gênero e reproduz ações esvaziadas de conteúdo teórico-metodológico e ético-político.

Por meio desta revisão integrativa, foi possível inferir que a temática é incipiente, mas também atual. Entende-se que para desvelar o trabalho do/a assistente social no que diz respeito à população trans e travesti é necessário, igualmente, levar em consideração a trajetória histórica de amadurecimento do Serviço Social, tanto do ponto de vista teórico quanto político. A baixa produção acadêmica revela que é preciso um esforço maior da categoria profissional em se aproximar das reflexões 
realizadas há décadas pelos movimentos sociais e pela população $\mathrm{T}$ de modo geral; ao mesmo tempo, também aponta possibilidades importantes de se realizar avanços.

Por meio do projeto ético-político da profissão, verifica-se que esta é uma temática relacionada intimamente aos princípios defendidos pelo Serviço Social. Por consequência, campo importante de atuação para os/ as assistentes sociais. Reconhecer a trans/travestifobia como expressão da questão social possibilita a imersão nos desdobramentos da relação capital e trabalho. Esse reconhecimento é fundamental para compreender a origem dos desafios, estruturais e situacionais, com os quais se depara o/a assistente social nos espaços ocupacionais.

Tendo isso em mente, é possível pensar, em conjunto com outros profissionais e com os/as usuários/as dos serviços, estratégias e possibilidades de atuação que tenham a capacidade de transformar a realidade, sem perder de vista os limites impostos ao profissional de Serviço Social.

\section{Referências}

ABREU, Marina Maciel. Serviço Social e a organização da cultura: perfis pedagógicos da prática profissional. São Paulo: Cortez, 2002.

BARROCO, Maria Lúcia Silva. Fundamentos éticos do Serviço Social. In: CFESS; ABEPSS. Serviço Social: direitos sociais e competências profissionais. Brasília: ABEPSS, 2009.

BENEVIDES, Bruna; NOGUEIRA, Sayonara Naider Bonfim. Dossiê dos assassinatos e da violência contra travestis e transexuais brasileiras em 2019. São Paulo: Expressão Popular; ANTRA; IBTE, 2020. Disponível em: https://antrabrasil.files.wordpress.com/2020/01/ dossic3aa-dos-assassinatos-e-da-violc3aancia-contra-pessoas-trans-em-2019.pdf. Acesso em: 7 jan. 2021.

BENTO, Berenice. A (re)invenção do corpo: sexualidade e gênero na experiência transexual. Rio de Janeiro: Garamond, 2006.

BENTO, Berenice. O que é transexualidade. São Paulo: Brasiliense, 2008.

BRASIL. Código de ética do/a assistente social: Lei 8.622/93 de regulamentação da profissão. 10. ed. rev. e atual. Brasília: Conselho Federal de Serviço Social, 2012. Disponível em: http://www.cfess.org.br/arquivos/CEP_CFESS-SITE.pdf. Acesso em: 8 nov. 2020. 
CISNE, Mirla; SANTOS, Silvana Mara Morais dos. Feminismo, diversidade sexual e Serviço Social. São Paulo: Cortez, 2018. v. 8. (Biblioteca Básica do Serviço Social).

CONSELHO FEDERAL DE SERVIÇO SOCIAL (CFESS). Parâmetros para atuação de assistentes sociais na saúde. Brasília: CFESS, 2010.

CONSELHO FEDERAL DE SERVIÇO SOCIAL (CFESS). Transfobia. Brasília: CFESS, 2016. (Série Assistente Social no Combate ao Preconceito),

CONSELHO FEDERAL DE SERVIÇO SOCIAL (CFESS). Resolução n. 845, de 26 de fevereiro de 2018. Dispõe sobre atuação profissional do/a assistente social em relação ao processo transexualizador. Brasília, 2018. Disponível em: http://www.cfess.org.br/arquivos/ ResolucaoCfess845-2018.pdf. Acesso em: 12 set. 2020.

IAMAMOTO, Marilda Villela. O Serviço Social na contemporaneidade: trabalho e formação profissional. 3. ed. São Paulo: Cortez, 2000.

IAMAMOTO, Marilda Villela. O Serviço Social na cena contemporânea. In: CFESS; ABEPSS. Curso de especialização: direitos sociais e competências profissionais. Brasília: [s. n.], 2009.

MARINHO, Silvana. Serviço Social e população trans: um debate sobre questão social e suas expressões na cena contemporânea. Serviço Social em Perspectiva, v. 1, n. 1, p. 103125, jan./jun. 2017. Disponível em: https://www.periodicos.unimontes.br/index.php/ sesoperspectiva/article/view/799. Acesso em: 7 nov. 2020.

MENDES, Karina Dal Sasso; SILVEIRA, Renata Cristina de Campos Pereira; GALVÃO, Cristina Maria. Revisão integrativa: método de pesquisa para a incorporação de evidências na saúde e na enfermagem. Texto \& Contexto: Enfermagem, v. 17, n. 4, p. 758-764, 2008. Disponível em: https://www.scielo.br/pdf/tce/v17n4/18.pdf. Acesso em: 2 jul. 2020.

NETTO, José Paulo. Cinco notas a propósito da questão social. Temporalis, Brasília, n. 3, p. 41-50, 2001.

NETTO, José Paulo. A construção do projeto ético político do Serviço Social. In: MOTA, A. E. et al. Serviço Social e saúde: formação e trabalho profissional. São Paulo: Cortez, 2006.

PONTES, Reinaldo. A categoria de mediação em face do processo de intervenção do Serviço Social. Boletim Eletrônico Surá, San José, n. 31, p. 6, 1999. Disponível em: http:// www.ts.ucr.ac.cr/binarios/sura/sura-0031.pdf. Acesso em: 7 jan. 2021.

RICARDO, Kellyane de Santana. A atuação do Serviço Social no processo de trabalho na saúde e o processo transexualizador no SUS: interlocuções com a experiência do Espaço Trans - Hospital das Clínicas - UFPE. Serviço Social em Perspectiva, v. 3, n. 1, p. 61-80, jan./jun. 2019. Disponível em: https://www.periodicos.unimontes.br/index.php/ sesoperspectiva/article/view/255/288. Acesso em: 7 nov. 2020. 
ROCON, Pablo Cardozo; SODRÉ, Francis; DUARTE, Marco José de Oliveira. Questões para o trabalho profissional do assistente social no processo transexualizador. Katálysis, Florianópolis, v. 21, n. 3, p. 523-533, dez. 2018. Disponível em: https:/www.scielo.br/pdf/ rk/v21n3/1982-0259-rk-21-03-00523.pdf. Acesso em: 6 nov. 2020.

SANTOS, Cláudia Mônica dos. Na prática a teoria é outra?: mitos e dilemas na relação entre teoria, prática, instrumentos e técnicas no Serviço Social. Rio de Janeiro: Lumen Juris, 2011.

SANTOS, Thais Felipe Silva dos; MARTINELLI, Maria Lúcia. A sociabilidade das pessoas travestis e transexuais na perícia social. Serviço Social \& Sociedade, São Paulo: Cortez, n. 134, p. 142-160, 2019. Disponível em: https:/www.scielo.br/pdf/sssoc/n134/01016628-sssoc-134-0142.pdf. Acesso em: 2 nov. 2020.

SILVA, Anabella Pavão da; LEHFELD, Neide Aparecida de Souza. Breves compreensões sobre as "cores" da diversidade sexual e de gênero: situando o Serviço Social. Temporalis, v. 19, n. 37, p. 102-117, 2019. Disponível em: https://www.periodicos.ufes.br/index.php/ temporalis/article/view/24025. Acesso em: 9 jan. 2021.

SOUZA, Marcela Tavares de; SILVA, Michelly Dias da; CARVALHO, Rachel de. Revisão integrativa: o que é e como fazer. Einstein, São Paulo, v. 8, n. 1, p. 102-106, mar. 2010. Disponível em: https://www.scielo.br/pdf/eins/v8n1/pt_1679-4508-eins-8-1-0102. Acesso em: 30 set. 2020 .

\section{Sobre as autoras}

Bárbara Cristina Silva Pereira - Assistente Social. Especialista em Saúde da Mulher.

E-mail: barbarapereira.ss@outlook.com

Silse Teixeira de Freitas Lemos - Doutora em Serviço Social. Professora-associada do Departamento de Serviço Social e docente da Residência Multiprofissional em Saúde do Hospital Universitário Presidente Dutra.

E-mail: silselemos@gmail.com 